\title{
Modulation of Plasticity in Human Motor Cortex after Forearm Ischemic Nerve Block
}

\author{
Ulf Ziemann, Brian Corwell, and Leonardo G. Cohen \\ Human Cortical Physiology Unit, National Institutes of Neurological Disorders and Stroke, National Institutes of Health, \\ Bethesda, Maryland 20892
}

\begin{abstract}
Deafferentation leads to cortical reorganization that may be functionally beneficial or maladaptive. Therefore, we were interested in learning whether it is possible to purposely modulate deafferentation-induced reorganization. Transient forearm deafferentation was induced by ischemic nerve block (INB) in healthy volunteers. The following five interventions were tested: INB alone; INB plus low-frequency $(0.1 \mathrm{~Hz})$ repetitive transcranial magnetic stimulation of the motor cortex ipsilateral to INB $\left(\right.$ INB $\left.+r T M S_{i}\right) ; r T M S_{i}$ alone; INB plus rTMS of the motor cortex contralateral to INB (INB+rTMS $)$; and $\mathrm{rTMS}_{\mathrm{c}}$ alone. Plastic changes in the motor cortex contralateral to deafferentation were probed with TMS, measuring motor threshold (MT), motor evoked-potential (MEP) size, and intracortical inhibition (ICI) and facilitation (ICF) to the biceps brachii muscle proximal to the level of deafferentation. INB alone induced a moderate increase in MEP size, which was significantly enhanced by INB + TTMS $_{\mathrm{c}}$ but blocked by INB $+\mathrm{rTMS}_{\mathrm{i}}$. INB alone had no
\end{abstract}

effect on $\mathrm{ICl}$ or $\mathrm{ICF}$, whereas $\mathrm{INB}+\mathrm{rTMS}_{\mathrm{C}}$ reduced $\mathrm{ICl}$ and increased ICF, and conversely, INB + TTMS $_{\mathrm{i}}$ deepened ICI and suppressed ICF. $r T M S_{i}$ and rTMS $_{c}$ alone were ineffective in changing any of these parameters. These findings indicate that the deafferented motor cortex becomes modifiable by inputs that are normally subthreshold for inducing changes in excitability. The deafferentation-induced plastic changes can be up-regulated by direct stimulation of the "plastic" cortex and likely via inhibitory projections down-regulated by stimulation of the opposite cortex. This modulation of cortical plasticity by noninvasive means might be used to facilitate plasticity when it is primarily beneficial or to suppress it when it is predominately maladaptive.

Key words: motor cortical excitability; cortical reorganization; transient forearm deafferentation; ischemic nerve block; human; transcranial magnetic stimulation; modulation of plasticity
Reorganization in the sensory and motor cortices in the adult mammalian CNS is possible, either in response to lesions of peripheral or central structures or as a consequence of learning (Kaas, 1991; Pons et al., 1991; Garraghty and Kaas, 1992; Sanes and Donoghue, 1992, 1997; Merzenich and Jenkins, 1993, 1995; Donoghue, 1995; Rauschecker, 1995; Nudo et al., 1996; Dinse et al., 1997; Kaas and Florence, 1997). Plastic changes, defined as any enduring changes in cortical properties like strength of internal connections, representational patterns, or neuronal properties, either morphological or functional (Donoghue et al., 1996), can be beneficial or maladaptive. As an example of beneficial plasticity, congenitally or early blind patients show cross-modal activation of the visual cortex when reading Braille (Sadato et al., 1996), which is functionally relevant because their Braille reading ability can be specifically disrupted by repetitive transcranial magnetic stimulation (rTMS) over the visual cortex (Cohen et al., 1997). As a likely example of maladaptive plasticity, the extent of medial extension of the face representation into the deafferented hand area of the somatosensory cortex in upper limb amputees correlates strongly with the intensity of phantom limb pain (Flor et al., 1995; Knecht et al., 1996; Birbaumer et al., 1997). Further

\footnotetext{
Received Aug. 8, 1997; revised Nov. 3, 1997; accepted Nov. 7, 1997.

This work was supported by Grant Zi 542/1-1 (U.Z.) from the Deutsche Forschungsgemeinschaft. We thank Mark Hallett for support and discussions.

Correspondence should be addressed to Dr. Ulf Ziemann or Dr. Leonardo G. Cohen, Building 10, Room 5N234, National Institutes of Health, 10 Center Drive, MSC-1430, Bethesda, MD 20892-1428.

Copyright (C) 1998 Society for Neuroscience $\quad 0270-6474 / 98 / 181115-09 \$ 05.00 / 0$
}

more, this type of cortical reorganization can be associated with misperceptions in the phantom limb when touching the face ipsilateral to the amputation (Ramachandran et al., 1992; Ramachandran, 1994; Yang et al., 1994). Therefore, it would be desirable to find strategies for modulating cortical reorganization.

In animals, nerve lesions induce a rapid expansion of intact motor cortical representations into representational zones disconnected from the periphery by the nerve lesion (Sanes et al., 1988; Donoghue et al., 1990). In humans, transient ischemic limb deafferentation has been used as a model of reversible short-term plasticity. When tested with TMS during the course of deafferentation, it leads to a rapid increase in the motor cortical output to muscles proximal to the nerve block (Brasil-Neto et al., 1992, 1993; Ridding and Rothwell, 1995; Sadato et al., 1995). Increases in cortical excitability can also be obtained by repetitive cortical stimulation in animals (Nudo et al., 1990; Recanzone et al., 1992; Spengler and Dinse, 1994) and humans (Pascual-Leone et al., 1994; Tergau et al., 1997).

In the present study, we explored the possibility that lowfrequency $(0.1 \mathrm{~Hz})$ rTMS that does not induce changes in motor cortical excitability in the absence of deafferentation (Chen et al., 1997a) could modulate cortical excitability when applied with deafferentation. If so, this could indicate that the deafferented cerebral cortex shows an enhanced modifiability to otherwise subthreshold inputs. This modulation of cortical excitability may potentially be used to facilitate plasticity when it is primarily beneficial (Cohen et al., 1997) or to suppress it when it is possibly maladaptive (e.g., Flor et al., 1995). 


\section{MATERIALS AND METHODS}

\section{Subjects}

Seven healthy male volunteers (mean age, $28.9 \pm 8.4$ years; five were right-handed, and two were left-handed) participated in five experiments each. Another six volunteers were screened but excluded because the target muscle [biceps brachii (BB)] was primarily inexcitable by focal TMS of the contralateral motor cortex (four subjects) or because the subjects were unable to relax fully during forearm ischemia (two subjects). The subjects gave their written informed consent for the study, and the study protocol was approved by the Institutional Review Board.

\section{Measurements of motor excitability}

Subjects were seated in a comfortable reclining chair. Surface electromyogram (EMG) was recorded from the BB of the nondominant arm, using $\mathrm{Ag}-\mathrm{AgCl}$ cup electrodes in a belly-tendon montage. After amplification and bandpass $(100-2500 \mathrm{~Hz}$ ) filtering (Dantec Counterpoint Electromyograph; Dantec Electronics, Skovlunde, Denmark), raw signals were fed into an IBM/386 AT-compatible laboratory computer for further off-line analysis. Magstim 200 magnetic stimulators (Magstim, Whitland, Dyfed, United Kingdom) and a figure-of-eight (70 $\mathrm{mm}$ ) stimulation coil (peak magnetic field, 2.2 tesla) were used for TMS at the optimal position on the scalp for activating the contralateral BB. The handle of the coil pointed backward and $\sim 45^{\circ}$ lateral from the midline. The current thus induced in the brain flows approximately perpendicular to the line of the central sulcus, which leads to predominately trans-synaptic activation of the corticospinal system (Kaneko et al., 1996). The optimal scalp position was marked with a pen to ensure the same coil placement throughout the experiment. As measures of motor excitability, motor threshold (MT), motor evoked-potential (MEP) size, intracortical inhibition (ICI), and intracortical facilitation (ICF) were determined. MT reflects primarily neuronal membrane excitability (Mavroudakis et al., 1994; Ziemann et al., 1996b; Chen et al., 1997b), and ICI and ICF probe mainly trans-synaptic excitability of inhibitory and excitatory interneuronal circuits at the motor cortex level (Kujirai et al., 1993; Rothwell, 1996; Ziemann et al., 1996c). MEP size depends on the excitability through all stages of the motor system. MT that was determined to the nearest $1 \%$ of the maximum stimulator output was defined as the minimum intensity required to produce MEPs of $>50 \mu \mathrm{V}$ in 5 out of 10 trials. Thereafter, MEP size was determined by averaging peak-to-peak MEP amplitudes over five single trials each at stimulus intensities of 15 , 20 , and $30 \%$ of maximum stimulator output above MT.

Intracortical excitability was determined primarily according to a previously reported paired conditioning-test stimulus paradigm (Kujirai et al., 1993; Ziemann et al., 1996c) using a BiStim module (Magstim) to connect two magnetic stimulators to one figure-of-eight coil. The intensity of the conditioning stimulus was set at $80 \%$ of the MT of a hand muscle (abductor pollicis brevis, APB). This avoided safely a significant activation of the corticospinal system to the BB (Kujirai et al., 1993), the MT of which is usually slightly higher than that of the APB (Brouwer and Ashby, 1990) (in our study, $50.0 \pm 5.0$ vs $44.7 \pm 5.2 \%$ ). The intensity of the test stimulus was set to produce alone on average a test MEP size in the BB of $200-400 \mu \mathrm{V}$. Any changes in test MEP size by intervention (see below) were counterbalanced by adjustments in test stimulus intensity to keep the test MEP size constant throughout the experiment. Two inhibitory (2 and $4 \mathrm{msec}$ ) (Kujirai et al., 1993; Ziemann et al., 1996c) and two facilitatory (10 and $15 \mathrm{msec}$ ) (Kujirai et al., 1993; Ziemann et al., 1996c) interstimulus intervals (ISIs) were randomly intermixed with control trials (test stimulus alone). Eight trials were recorded for each condition. The size of the conditioned mean MEPs was expressed as a percentage of the control mean MEP.

All parameters of motor excitability were tested with the target muscle (BB) at rest. Complete voluntary relaxation was monitored by continuous EMG at a high gain $(50 \mu \mathrm{V} / \mathrm{Div})$, and the EMG signal was played through a loudspeaker as a feedback to the subjects. Trials with any sign of incomplete relaxation were discarded from further analysis to avoid unspecific MEP facilitation (e.g., Hess et al., 1986) or an unspecific decrease in ICI and ICF (Ridding et al., 1995).

\section{Interventions}

Immediately after these baseline measurements, one of five interventions was applied. All seven subjects participated in all five experiments, with a break between successive sessions of a least $3 \mathrm{~d}$ (maximum 2 weeks). The order of experiments was pseudorandomized between subjects to avoid any possible ordering effect. The interventions were as follows: (1) ischemic nerve block (INB) alone, (2) INB plus low-frequency $(0.1 \mathrm{~Hz})$ repetitive transcranial magnetic stimulation of the motor cortex ipsilat-

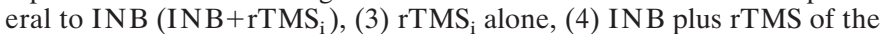
motor cortex contralateral to INB (INB $+\mathrm{rTMS}_{\mathrm{c}}$ ), and (5) rTMS $\mathrm{c}$ alone.

INB alone. A tourniquet was inflated above systolic blood pressure $(220-250 \mathrm{mmHg})$ across the elbow distal to the target BB. The pressure level was kept constant until complete INB to the APB was achieved $(31.7 \pm 3.8 \mathrm{~min})$. An additional $5 \mathrm{~min}$ were waited before the excitability parameters (MT, MEP size, ICI, and ICF) were remeasured. Immediately after these measurements were made, the tourniquet was gradually released over a period of $2-3 \mathrm{~min}$. The excitability parameters were remeasured 20, 40, and $60 \mathrm{~min}$ after tourniquet deflation was started. The same timing for remeasurements was used also for all other interventions.

$I N B+r T M S_{i}$. INB was achieved as described for intervention 1. In addition, the motor cortex ipsilateral to the deafferented arm was stimulated repetitively at a rate of $0.1 \mathrm{~Hz}$ and an intensity of $120 \%$ of MT for the BB from the onset of ischemia until complete INB $(31.0 \pm 4.7 \mathrm{~min})$. This low stimulus rate was chosen because previous experiments demonstrated no effect on motor excitability in the absence of INB (Chen et al., 1997a). Thus, any effect of TMS in the presence of forelimb INB would indicate that the deafferentation rendered motor cortex excitability more modifiable to normally inert input. For rTMS, a water-cooled figure-of-eight coil and a Cadwell rapid-rate magnetic stimulator (Cadwell Laboratories Inc., Kennewick, WA) were used. The coil was placed at a site optimal for activation of the BB on the nonischemic side.

$r T M S_{i}$ alone. As a control experiment for intervention 2, rTMS was applied for $\sim 30 \mathrm{~min}$ to the motor cortex ipsilateral to the target BB at the same stimulus rate and intensity used for intervention 2 but without INB.

$I N B+r T M S_{c}$. INB was achieved as described for intervention 1 , but rTMS $(0.1 \mathrm{~Hz} ; 120 \%$ of MT for the BB) was applied to the motor cortex contralateral to the deafferented arm. The average time to complete INB was $32.7 \pm 4.0 \mathrm{~min}$.

$r T M S_{c}$ alone. As a control experiment for intervention 4, rTMS was applied to the motor cortex contralateral to the target BB as described for intervention 4 but in the absence of INB. The rationale for applying rTMS to the motor cortex ipsilateral to deafferentation was based on the reported predominately inhibitory effect of stimulation of one motor cortex on MEP induced by stimulation of the other motor cortex (Ferbert et al., 1992; Meyer et al., 1995; Netz et al., 1995). Conversely, rTMS of the motor cortex contralateral to deafferentation should exert a predominately facilitatory effect via repeated synchronized activation of the motor representation to the target BB.

In a different experiment (five subjects), we documented the intensity of pain associated with INB and measures of motor excitability, comparing three different interventions: INB alone, INB $+\mathrm{rTMS}_{\mathrm{i}}$, and INB $+\mathrm{rTMS}_{\mathrm{c}}$. The intensity of pain from the ischemic forearm was scaled by means of a standardized psychophysical pain ratio-scale (Max et al., 1992) with good internal consistency, reliability, and objectivity (Gracely et al., 1978).

Statistical analysis. Motor excitability parameters (MT, MEP size, ICI, and ICF) were analyzed separately. MT data were expressed as changes from baseline (in percentage of maximum stimulator output); all other data were normalized to baseline to eliminate interindividual differences in absolute values. For the evaluation of the effect of intervention and time after intervention, two-way ANOVAs were calculated using a model of repeated measures. Conditional on significant $F$ values, post hoc $t$ tests were performed. Adjustment for multiple comparisons was made by the method of Bonferroni. Results were considered significant if $p<0.05$.

\section{RESULTS}

Intervention had no significant effect on $\mathrm{MT}\left[F_{\text {intervention }(4,30)}=\right.$ $0.42]$, but the effect of time was significant $\left[F_{\text {time }(3,30)}=3.25 ; p=\right.$ $0.026]$. The interaction between intervention and time was not significant $\left[F_{(12,90)}=1.39\right]$. The two interventions involving INB plus rTMS of the motor cortex ipsilateral or contralateral to the INB showed a nonsignificant trend toward a transient increase in MT late into ischemia (Fig. 1).

Intervention and time had a significant effect on MEP size $\left[F_{\text {intervention }(4,90)}=4.64 ; p=0.0019 ; F_{\text {time }(3,90)}=3.11 ; p=0.027\right]$, but the effect of stimulus intensity $(15,20$, and $30 \%$ above MT) was not significant $\left[F_{\text {intensity(2,90) }}=1.42\right]$. Therefore, data were pooled across stimulus intensities for further analysis. Post hoc 


\section{Motor threshold}

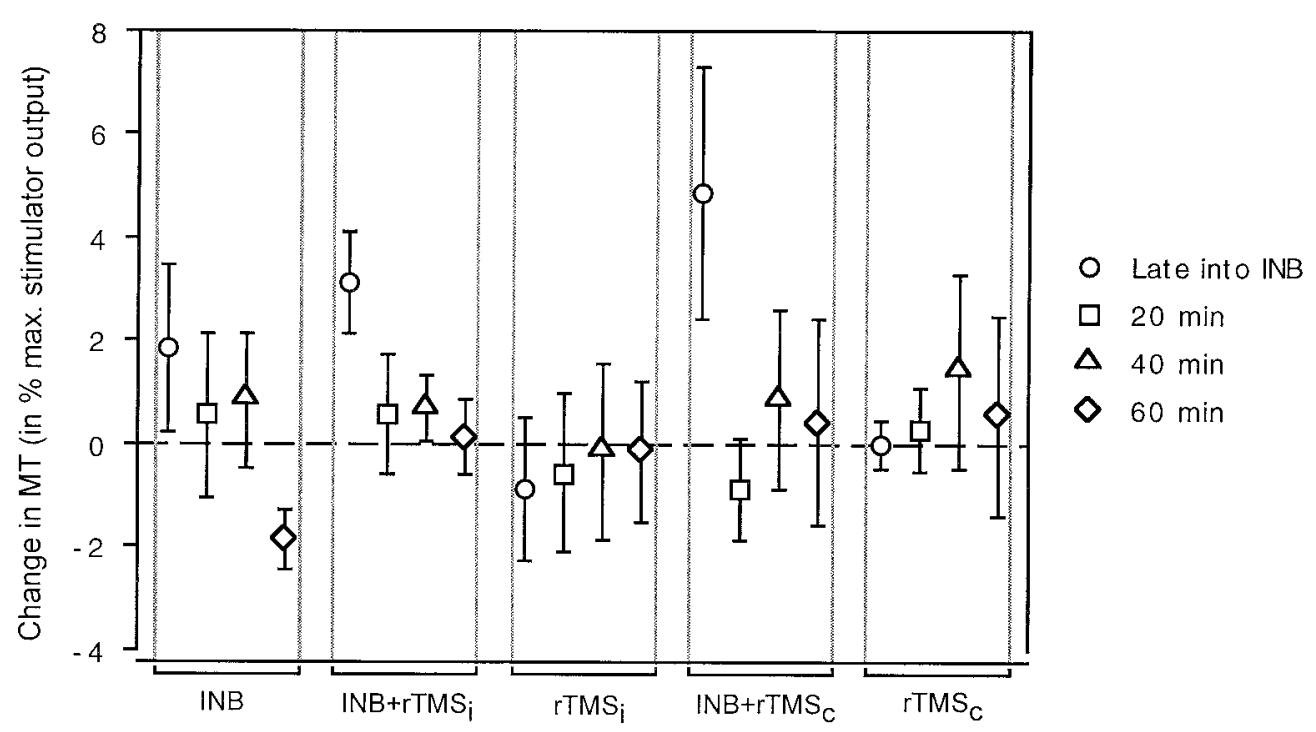

Figure 1. Changes in MT of the target biceps brachii muscle produced by the different interventions plotted on the $x$-axis $(I N B$, ischemic nerve block alone; $I N B+r T M S_{i}$, INB plus repetitive transcranial magnetic stimulation of the motor cortex ipsilateral to INB; $r T M S_{i}$, same stimulation without INB; INB+rTMS INB plus rTMS of the motor cortex contralateral to INB; and $r T M S_{c}$, same stimulation without INB). Changes in MT measured late into intervention (circles) and 20 (squares), 40 (triangles), and 60 min after intervention (diamonds) compared with baseline (before intervention) are given as a percentage of maximum stimulator output on the $y$-axis. Data are mean values of seven subjects; error bars indicate SE.

\section{Motor evoked potential size}

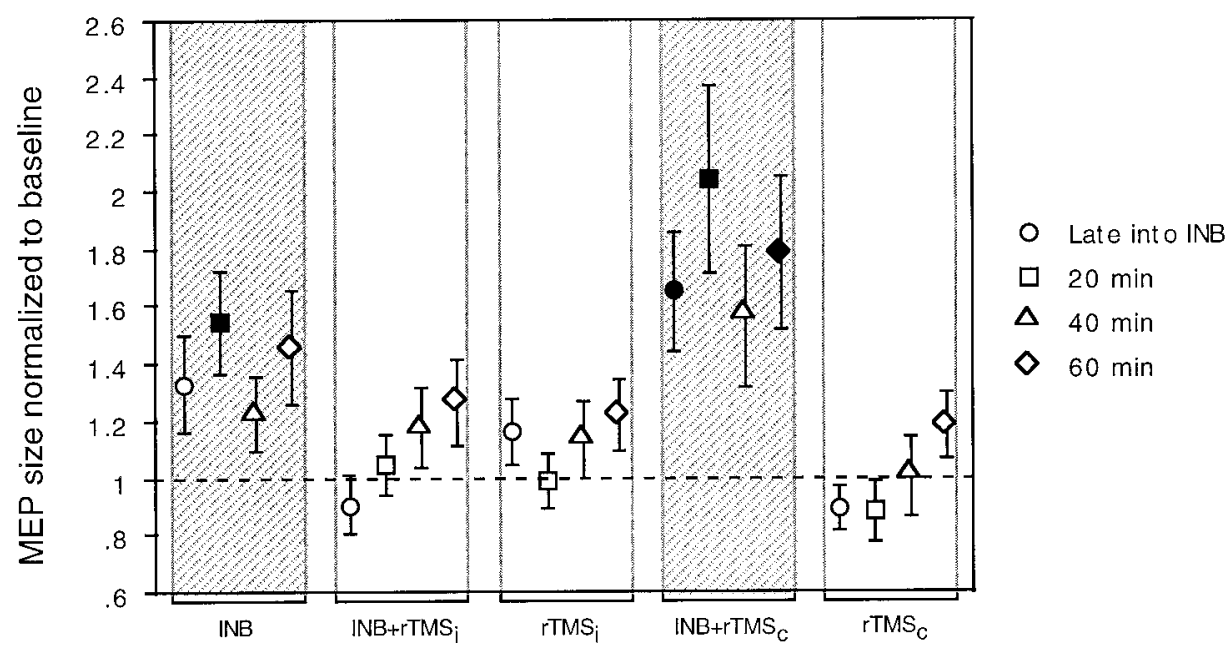

Figure 2. Changes in MEP size produced by the different interventions given on the $x$-axis. Data are expressed as values normalized to a baseline that has been assigned a value of 1 . Gray columns indicate interventions that induced a significant change in MEP size; filled symbols indicate time points that were significantly different from baseline. Other conventions and arrangements are as described in Figure 1.

comparisons showed that INB alone and $\mathrm{INB}+\mathrm{rTMS}_{\mathrm{c}}$ were different from all other interventions and also different from each other (Fig. 2). Both interventions produced a significant increase in MEP size $(t=4.54$ and $p<0.0001$ for INB alone; $t=5.76$ and $p<0.0001$ for INB $\left.+\mathrm{rTMS}_{\mathrm{c}}\right)$. Quantitatively, this facilitatory effect was stronger for INB+rTMS than for INB alone (1.76 1.21 vs $1.39 \pm 0.78$, respectively; values are MEP sizes normalized to baseline). The facilitatory effect was present for at least 60 min after intervention (Fig. 2). All other interventions had no significant effect on MEP size. In summary, rTMS of the motor cortex ipsilateral to ischemia blocked the increase in MEP size observed with INB alone, whereas rTMS of the cortex contralateral to ischemia enhanced it.

Intervention had a significant effect on ICI $\left[F_{\text {intervention }(4,60)}=\right.$ $5.15 ; p=0.0012]$, but the effects of time and interstimulus interval $(2$ and $4 \mathrm{msec})$ were not significant $\left[F_{\text {time }(3,60)}=0.47 ; F_{\text {ISI }(1,60)}=\right.$ $0.50]$. Therefore, data were pooled across times and interstimulus intervals for further analysis. Post hoc comparisons showed that INB $+\mathrm{rTMS}_{\mathrm{c}}$ was significantly different from most of the other interventions $\left(\mathrm{INB}+\mathrm{rTMS}_{\mathrm{i}}\right.$; $\mathrm{rTMS}_{\mathrm{i}}$; and $\mathrm{rTMS}_{\mathrm{c}} ; p<0.001$ for all comparisons). After INB+rTMS , ICI was reduced over the full course of $60 \mathrm{~min}$, whereas all other interventions had no significant effect on ICI (Fig. $3 A$ ). INB + rTMS $_{\mathrm{i}}$ caused a transient increase in ICI late into the intervention (Fig. $3 A$ ). In summary, INB $+\mathrm{rTMS}_{\mathrm{c}}$ induced a prolonged decrease in ICI, INB $+\mathrm{rTMS}_{\mathrm{i}}$ led to a transient increase in ICI, whereas the other interventions had no significant effect.

Intervention had a significant effect on $\operatorname{ICF}\left[F_{\text {intervention }(4,60)}=\right.$ $3.20 ; p=0.019]$. Because time and interstimulus intervals (10 and $15 \mathrm{msec})$ had no effect $\left[F_{\text {time }(3,60)}=0.37 ; F_{\text {ISI }(1,60)}=0.18\right]$, data were pooled across times and interstimulus intervals for further analysis. Post hoc comparisons revealed that the effects of $\mathrm{INB}+\mathrm{rTMS}_{\mathrm{c}}$ and INB $+\mathrm{rTMS}_{\mathrm{i}}$ were significantly different from all other interventions and also different from each other. $\mathrm{INB}+\mathrm{rTMS}_{\mathrm{c}}$ produced a prolonged (at least $60 \mathrm{~min}$ ) increase in ICF (Fig. $3 B$ ). In contrast, INB + rTMS $_{i}$ led to significant suppression of ICF (significant until $20 \mathrm{~min}$ after intervention). The other interventions had no significant effect on ICF (Fig. 3B). 

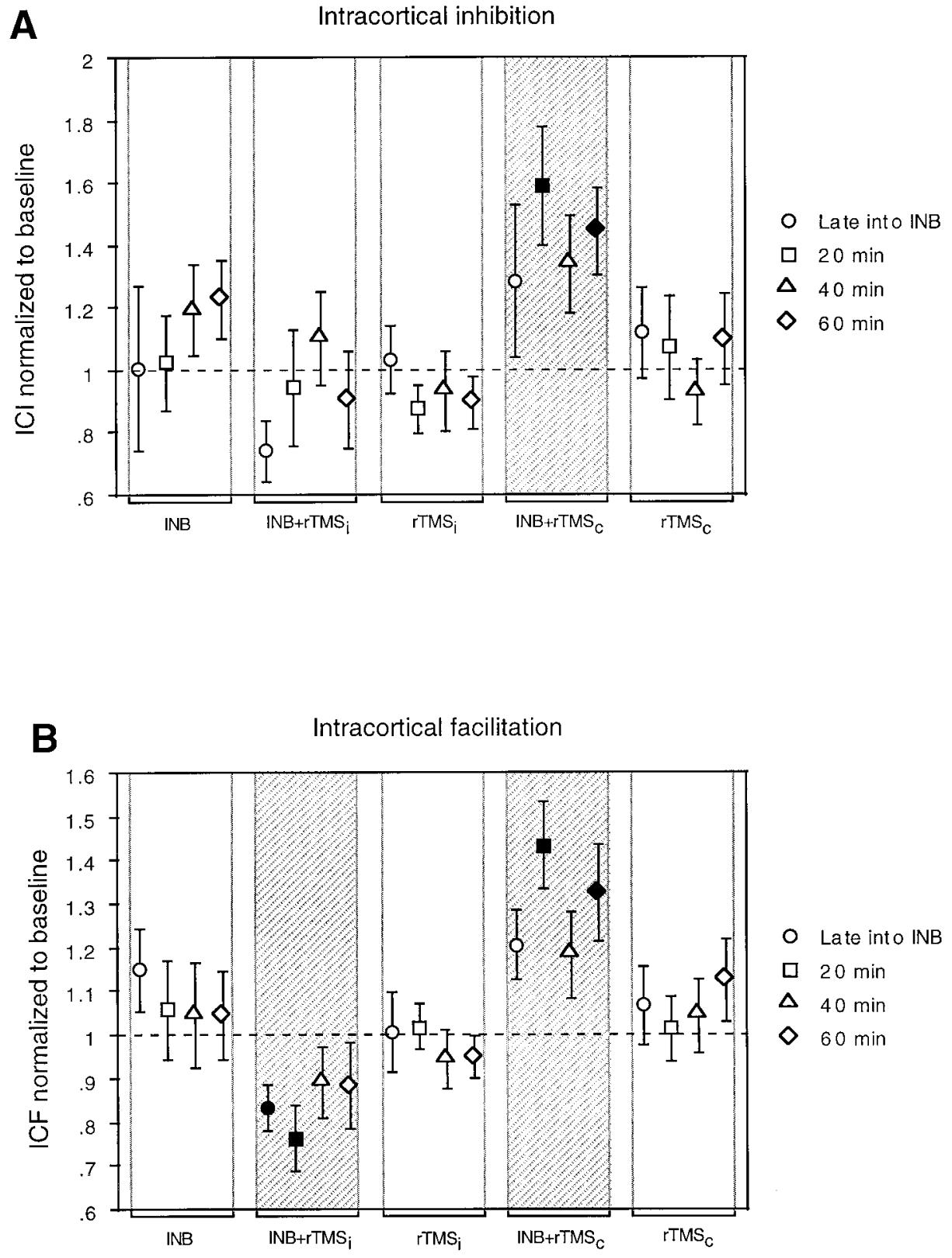

Figure 3. $A, B$, Changes in ICI and ICF produced by the different interventions given on the $x$-axis. Data are expressed as values normalized to a baseline that has been assigned a value of 1 . Other conventions and arrangements are as described in Figures 1 and 2.
The main findings on the group data are illustrated further by MEP recordings from a single subject (Fig. 4). Baseline MEP size at $20 \%$ above MT (Fig. $4 A$ ) and ICI (ISI of $2 \mathrm{msec}$ ) and ICF (ISI of $10 \mathrm{msec}$; Fig. $4 B$ ) are shown for the two most contrasting interventions (left, INB $+\mathrm{rTMS}_{\mathrm{i}}$; right, $\mathrm{INB}^{\mathrm{INTMS}} \mathrm{c}$ ) as a comparison between recordings at baseline and late into ischemia. INB + rTMS $_{i}$ had no effect on MEP size, whereas INB + rTMS $_{\mathrm{c}}$ produced a clear increase (Fig. $4 A$ ). INB + rTMS $_{\mathrm{i}}$ induced a deepening of ICI and a decrease in ICF. In contrast, INB $+\mathrm{rTMS}_{\mathrm{c}}$ led to a decrease in ICI and a slight enhancement of ICF (Fig. $4 B$ ).

The time until complete motor block was achieved, the total time of forearm ischemia, and the duration of rTMS were not different across interventions (Table 1). There was no significant difference for any of the excitability parameters at baseline across interventions (Table 2).

The intensity of ischemia-induced pain was evaluated together with changes in motor excitability in an additional set of experiments. Whereas MEP, ICI, and ICF were oppositely modulated by INB $+\mathrm{rTMS}_{\mathrm{c}}$ and INB $+\mathrm{rTMS}_{\mathrm{i}}(t=3.40$ and $p=0.0012 ; t=$ 4.40 and $p<0.0001$; and $t=17.65$ and $p<0.0001$, respectively), replicating the results of the previous experiment, intensity of pain was very similar across the three interventions $(9.0 \pm 3.5$ for INB alone; $9.8 \pm 3.4$ for $\mathrm{INB}+\mathrm{rTMS}_{\mathrm{i}}$; and $10.0 \pm 0.7$ for $\left.\mathrm{INB}+\mathrm{rTMS}_{\mathrm{c}} ; F_{\text {intervention(2,8) }}=0.15, \mathrm{NS}\right)$. Therefore, the differences in motor excitability reported across interventions were not caused by differences in pain intensity.

\section{DISCUSSION}

Transient ischemic forearm deafferentation increased the modifiability of contralateral motor cortical excitability to different interventions. Low-frequency rTMS $(0.1 \mathrm{~Hz})$, which is normally subthreshold for inducing changes in excitability, became effective in modulating deafferentation-induced cortical plasticity, depending on the predominantly excitatory (rTMS of the "plastic" cortex) or inhibitory (rTMS of the opposite cortex) nature of the intervention. 
INB + rTMS $_{i}$

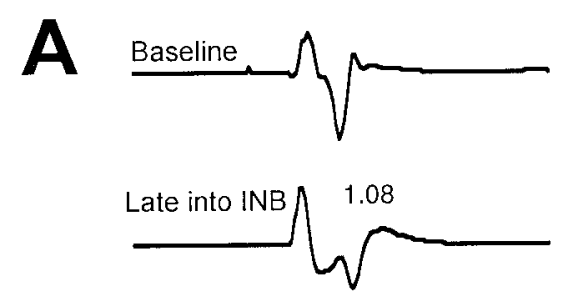

B
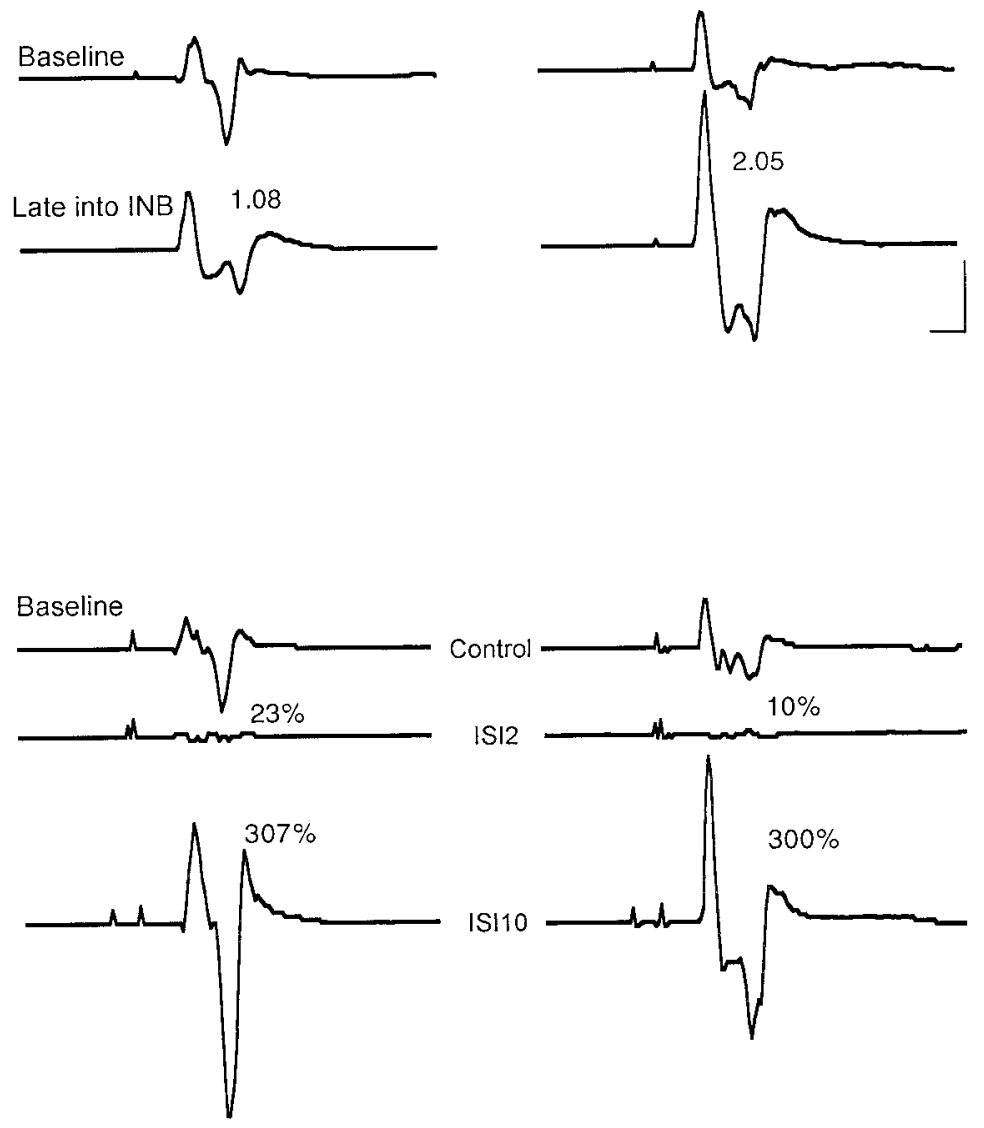

IS 110

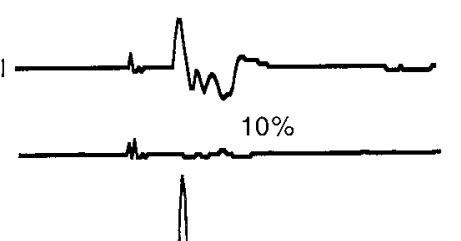

$300 \%$

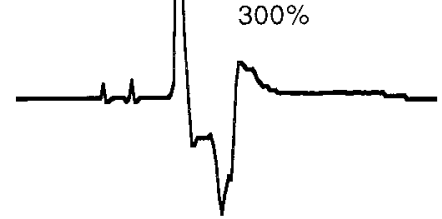

Late into INB

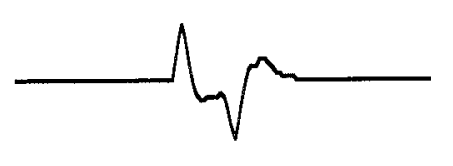

$5 \% / 0.21$

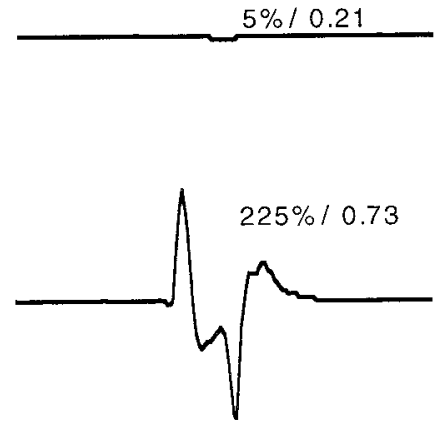

Control

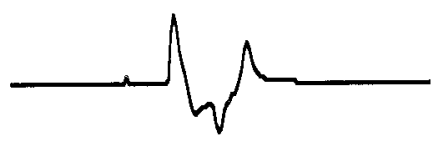

$\mathrm{IS} 12$

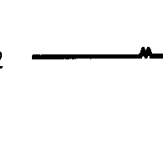

IS 110

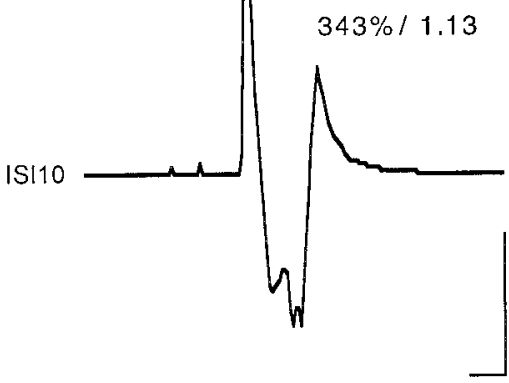

Figure 4. A, MEP recordings from the biceps brachii muscle of one representative subject at baseline (top traces) and $\sim 50$ min into ischemic forearm deafferentation (bottom traces). rTMS at a stimulation rate of $0.1 \mathrm{~Hz}$ and a stimulus intensity of $20 \%$ above biceps motor threshold was delivered throughout ischemia either to the motor cortex ipsilateral $\left(r T M S_{i}\right)$ or contralateral $\left(r T M S_{c}\right)$ to ischemia. All EMG recordings are averages of 10 trials. Numbers in the bottom traces refer to the size of MEPs late into ischemia normalized to baseline. Calibration: $10 \mathrm{msec}, 1$ $\mathrm{mV}$. $B$, ICI and ICF measurements of the same subject described in $A$. MEPs to a single test stimulus (control) and conditioned by a preceding subthreshold stimulus at ISIs of 2 and $10 \mathrm{msec}$ (ISI2 and ISI10) are shown. Numbers at the conditioned MEPs indicate MEP size as a percentage of the control MEP. Late into intervention (bottom traces), ICI and ICF are also given relative to the baseline values. Note that the numbers do not always match exactly the MEPs shown. The latter are curve averages and therefore subject to phase cancellation, whereas the numbers refer to averages calculated from the single trials. Calibration bar, $10 \mathrm{msec}, 0.5 \mathrm{mV}$.

\section{Measures of motor cortex plasticity}

MT, which was unaffected by the different interventions, is thought to reflect mainly (postsynaptic) neuronal membrane excitability. It is elevated by sodium channel blockers like carbamazepine or phenytoin (Mavroudakis et al., 1994; Ziemann et al., 1996b; Chen et al., 1997b) but remains unchanged by GABAergic drugs like benzodiazepines or vigabatrin (Inghilleri et al., 1996; Ziemann et al., 1996a,b; Mavroudakis et al., 1997) and antiglutamatergic drugs like gabapentin or riluzole (Ziemann et al., 1996b; Liepert et al., 1998). Changes in MEP size from muscles immediately proximal to the level of deafferentation reflect changes in the excitability or in the representation of these mus- 


\begin{tabular}{|c|c|c|c|c|c|c|c|}
\hline & INB & $\mathrm{INB}+\mathrm{rTMS}_{\mathrm{i}}$ & $\mathrm{rTMS}_{\mathrm{i}}$ & $\mathrm{INB}+\mathrm{rTMS}_{\mathrm{c}}$ & $\mathrm{rTMS}_{\mathrm{c}}$ & $F$ & $p$ \\
\hline CMB & $31.7 \pm 3.8$ & $31.0 \pm 4.7$ & N/A & $32.7 \pm 4.0$ & N/A & 0.99 & NS \\
\hline TI & $48.0 \pm 4.1$ & $48.9 \pm 2.9$ & N/A & $49.9 \pm 5.2$ & N/A & 0.81 & NS \\
\hline STIM & N/A & $31.0 \pm 4.6$ & $30.3 \pm 0.8$ & $32.7 \pm 4.0$ & $30.2 \pm 0.4$ & 1.50 & NS \\
\hline
\end{tabular}

CMB, Time to complete motor block; TI, total time of ischemia; STIM, duration of rTMS; and N/A, not applicable. Values are means \pm SD (in minutes).

Table 2. Resting motor thresholds, MEP size, intracortical inhibition, and intracortical facilitation across interventions

\begin{tabular}{|c|c|c|c|c|c|c|c|}
\hline & INB & $\mathrm{INB}+\mathrm{rTMS}_{\mathrm{i}}$ & $\mathrm{rTMS}_{\mathrm{i}}$ & $\mathrm{INB}+\mathrm{rTMS}_{\mathrm{c}}$ & $\mathrm{rTMS}_{\mathrm{c}}$ & $F$ & $p$ \\
\hline MT (BB) & $51.4 \pm 6.4$ & $48.9 \pm 6.0$ & $49.3 \pm 4.8$ & $49.7 \pm 4.1$ & $50.9 \pm 4.2$ & 1.14 & NS \\
\hline MT (APB) & $46.0 \pm 6.7$ & $42.9 \pm 4.9$ & $46.3 \pm 4.6$ & $44.0 \pm 4.3$ & $44.4 \pm 5.9$ & 2.26 & NS \\
\hline MEP & $0.31 \pm 0.4$ & $0.35 \pm 0.21$ & $0.35 \pm 0.35$ & $0.34 \pm 0.33$ & $0.42 \pm 0.42$ & 0.62 & NS \\
\hline ICI & $51 \pm 20$ & $63 \pm 36$ & $62 \pm 30$ & $43 \pm 18$ & $53 \pm 27$ & 2.39 & NS \\
\hline ICF & $143 \pm 47$ & $165 \pm 65$ & $153 \pm 26$ & $149 \pm 68$ & $148 \pm 29$ & 1.60 & NS \\
\hline
\end{tabular}

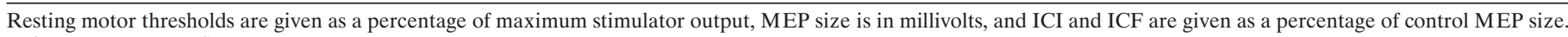
Values are means \pm SD.

cles at the level of the motor cortex (Brasil-Neto et al., 1993; Ridding and Rothwell, 1995). ICI and ICF as obtained in a conditioning-test stimulus paradigm (Kujirai et al., 1993; Ziemann et al., 1996c) reflect the excitability of separate inhibitory and excitatory interneuronal circuits in the motor cortex (for review, see Rothwell, 1996). Inhibitory or facilitatory mechanisms at a subcortical or spinal level do not contribute significantly, because the low-intensity conditioning stimulus does not affect spinal motoneuron excitability (Kujirai et al., 1993; Ziemann et al., 1996c) or motor responses evoked via direct activation of corticospinal neurons ("D waves") (Kujirai et al., 1993; Nakamura et al., 1995, 1997). In addition, neuropharmacological TMS studies showed that ICI can be enhanced and ICF suppressed by GABAergic (Ziemann et al., 1995, 1996a,b) and antiglutamatergic (Ziemann et al., 1996b; Liepert et al., 1998) drugs, whereas ion channel-blocking drugs had no effect (Ziemann et al., 1996b; Chen et al., 1997b), supporting further the "trans-synaptic nature" of ICI and ICF.

\section{Mechanisms and modulation of deafferentation-induced plasticity}

An increase in postsynaptic neuronal excitability has been advocated as a possible mechanism of plasticity, for instance in some forms of motor learning (Woody et al., 1991). In the present study, MT of the target biceps muscle was not significantly altered by any of the interventions. Therefore, as seen in motor cortex reorganization studies in rats (Sanes et al., 1990), a general change in neuronal membrane excitability can be dismissed here as a major factor causing the observed changes in motor excitability.

MEP size increased with forearm deafferentation plus rTMS of the plastic cortex and to a lesser extent with deafferentation alone, but this effect was blocked with rTMS applied to the motor cortex ipsilateral to deafferentation. The extrafacilitatory effect of plastic cortex stimulation is in line with the results of intracortical microstimulation experiments (ICMS) in rats, which showed that repetitive ICMS of a given representational area of the primary motor or somatosensory cortex induced a reversible enlargement of this particular representational map (Nudo et al., 1990; Recanzone et al., 1992; Spengler and Dinse, 1994). The authors hypothesized that these plastic changes were a consequence of the synchronized input spreading from the stimulation site into a local group of neurons of the interconnected network (for review, see Dinse et al., 1997). Although TMS is likely to induce a similarly synchronized activation of the cortex underneath the stimulation coil, the facilitatory effect of repetitive TMS in the current experiments was borne out only in the presence of forearm ischemia (see below). rTMS delivered to the motor cortex ipsilateral to ischemia attenuated the deafferentation-induced increase in MEP size. This is compatible with earlier reports on a predominately inhibitory effect of TMS of one motor cortex on MEPs induced by stimulation of the other motor cortex (Ferbert et al., 1992; Meyer et al., 1995; Netz et al., 1995).

ICI was decreased and ICF increased by ischemia combined with rTMS of the plastic motor cortex, whereas ischemia combined with rTMS of the opposite motor cortex induced a transient increase in ICI and a decrease in ICF. Ischemia alone or rTMS alone had no significant effect on ICI or ICF. When we consider that ICI and ICF are controlled by GABA and glutamate (see above), these results suggest that stimulation of the deafferented human motor cortical forearm and hand area down-regulates GABAergic function or up-regulates glutamatergic function or both. Stimulation of the opposite motor cortex exerts contrary effects, up-regulation of GABAergic and/or down-regulation of glutamatergic functions. Further differentiation between GABAor glutamate-mediated mechanisms, however, is not possible with the techniques used in the current experiments. The present findings fit the currently influential view that the modulation of GABA is key in mechanisms of short-term plasticity in the adult mammalian CNS (for review, see Garraghty and Kaas, 1992; Jones, 1993; Donoghue et al., 1996). This view was triggered mainly by the finding that pharmacological blockade of GABAreceptors by local application of bicuculline into adult rat forelimb motor cortex led to a "new" forelimb representation in the vibrissae cortex (Jacobs and Donoghue, 1991). This effect was interpreted as secondary to the unmasking of pre-existent excitatory connections from vibrissae to forelimb motor cortex, which normally are suppressed by local inhibitory circuits.

The main finding in this study is that it is possible to modulate plastic changes in the human motor cortex. Candidate mechanisms are strengthening (e.g., long-term potentiation, LTP) or weakening (e.g., long-term depression, LTD) pre-existent synaptic connections, because the observed time course of excitability 


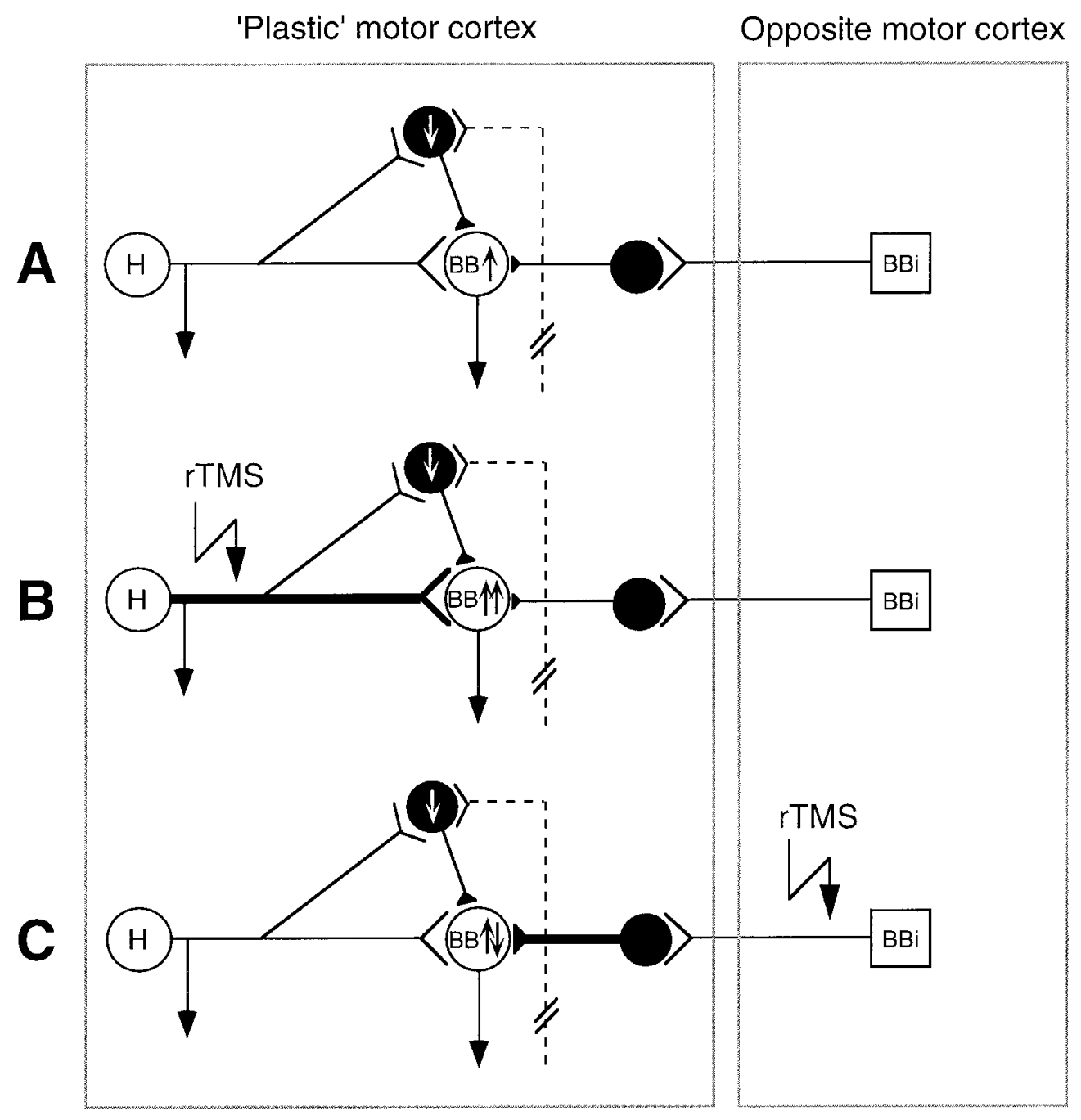

Figure 5. Model of intracortical connectivity (adopted from Jacobs and Donoghue, 1991) and hypothesized mechanisms of changes in motor cortex excitability induced by forearm deafferentation combined with rTMS. The plastic and opposite motor cortices are contralateral and ipsilateral to the deafferented forearm, respectively. Inhibitory interneurons are depicted as black circles, corticospinal neurons are open circles $(H, B B$, corticospinal neurons projecting to the ischemic hand and to the biceps brachii muscle, respectively), and an interhemispheric projection neuron $(B B i)$ is a square. $U p$ and down arrows inside neurons indicate up- and down-regulation of excitability of the corresponding neurons by deafferentation and rTMS. The dashed projection symbolizes the deafferented pathway from the ischemic forearm, projecting onto an inhibitory interneuron. $A$, The model assumes a latent excitatory projection from the hand to the biceps representation, which is normally nonfunctional because of inhibition via the inhibitory interneuron. Forearm deafferentation disinhibits this interneuron and in turn increases the overall excitability of the BB neuron. $B$, In the presence of this disinhibition, rTMS to the plastic motor cortex induces a strengthening of the excitatory projection from hand to BB corticospinal neurons (indicated by thickening of the corresponding axon). $C$, Conversely, rTMS of the opposite motor cortex leads to a strengthening of an inhibitory pathway (indicated by thickening of the corresponding axon of the inhibitory interneuron). It should be noted that the proposed model certainly is an oversimplification. Particularly, it was not intended to give the impression that the representations for hand versus upper arm are topographically separated in the human motor cortex. Recent primate (Donoghue et al., 1992) and human (Wassermann et al., 1992; Sanes et al., 1995) mapping experiments have clearly indicated a primarily overlapping representational organization for the hand and arm area that even may be a precondition for the plastic changes observed in the present study.

changes is too rapid to allow for structural reorganization, such as sprouting. The following model (in part adopted from Jacobs and Donoghue, 1991) may be formulated. (1) Hand and forearm deafferentation down-regulates inhibitory interneurons, which formerly received input from the hand or forearm, slightly weakening the overall level of inhibition of corticospinal neurons targeting the $\mathrm{BB}$ (Fig. 5A). This could explain the moderate increase in MEP size found in the $\mathrm{BB}$ with forearm ischemia alone. (2) In the presence of disinhibition of the pre-existent projection from hand and forearm to $\mathrm{BB}$ corticospinal neurons, synaptic strengthening of this projection in a LTP-like manner may be induced via its synchronized activation by rTMS (Fig. 5B). Such a potentiated pathway would explain the larger increase in MEP size compared with forearm ischemia alone and also the increase in ICF and the decrease in ICI. It was demonstrated only recently that LTP can be induced via horizontal connections of the mammalian neocortex (Iriki et al., 1989; Hess and Donoghue, 1994; Hess et al., 1996) and that LTP-like mechanisms are inducible by rTMS (Wang et al., 1996). Importantly, the induction of LTP was possible only if local inhibition at the recording site was suppressed (e.g., by the application of bicuculline) (Hess and Donoghue, 1994; Hess et al., 1996). This may explain why rTMS alone (at least with the stimulation rate and intensity used in the present experiments) was ineffective in facilitating motor cortical excitability. (3) If it is correct that the interaction between homonymous representation areas of the two primary motor cortices is predominately inhibitory (Ferbert et al., 1992; Meyer et al., 1995), then in the presence of disinhibition of the plastic motor cortex by forearm ischemia, the synchronized inhibitory input from the other motor cortex may lead to strengthening of these inhibitory projections in a LTDlike manner (Fig. 5C). Similar to that of LTP, the induction of LTD also requires sufficient postsynaptic depolarization of the target neuron (Artola et al., 1990; Hess and Donoghue, 1996), explaining again why rTMS alone was ineffective in strengthening inhibition.

In summary, our results indicate that it is possible to modulate cortical plasticity in humans using noninvasive techniques, an effect potentially relevant for studies of cognition and rehabilitation of function. 


\section{REFERENCES}

Artola A, Brocher S, Singer W (1990) Different voltage-dependent thresholds for inducing long-term depression and long-term potentiation in slices of rat visual cortex. Nature 347:69-72.

Birbaumer N, Lutzenberger W, Montoya P, Larbig W, Unertl K, Töpfner S, Grodd W, Taub E, Flor H (1997) Effects of regional anesthesia on phantom limb pain are mirrored in changes in cortical reorganization. J Neurosci 17:5503-5508.

Brasil-Neto JP, Cohen LG, Pascual-Leone A, Jabir FK, Wall RT, Hallett M (1992) Rapid reversible modulation of human motor outputs after transient deafferentation of the forearm: a study with transcranial magnetic stimulation. Neurology 42:1302-1306.

Brasil-Neto JP, Valls-Sole J, Pascual-Leone A, Cammarota A, Amassian VE, Cracco R, Maccabee P, Cracco J, Hallett M, Cohen LG (1993) Rapid modulation of human cortical motor outputs following ischaemic nerve block. Brain 116:511-525.

Brouwer B, Ashby P (1990) Corticospinal projections to upper and lower limb spinal motoneurons in man. Electroencephalogr Clin Neurophysiol 76:509-519.

Chen R, Classen J, Gerloff C, Celnik P, Wassermann EM, Hallett M, Cohen LG (1997a) Depression of motor cortex excitability by lowfrequency transcranial magnetic stimulation. Neurology 48:1398-1403.

Chen R, Samii A, Canos M, Wassermann EM, Hallett M (1997b) Effects of phenytoin on cortical excitability in humans. Neurology 49:881-883.

Cohen LG, Celnik P, Pascual-Leone A, Corwell B, Faiz L, Dambrosia J, Honda M, Sadato N, Gerloff C, Catala MD, Hallett M (1997) Functional relevance of cross-modal plasticity in the blind. Nature 389:180-183.

Dinse HR, Godde B, Hilger T, Haupt SS, Spengler F, Zepka R (1997) Short-term functional plasticity of cortical and thalamic sensory representations and its implication for information processing. Adv Neurol 73:159-178.

Donoghue JP (1995) Plasticity of adult sensorimotor representations. Curr Opin Neurobiol 5:749-754.

Donoghue JP, Suner S, Sanes JN (1990) Dynamic organization of primary motor cortex output to target muscles in adult rats. II. Rapid reorganization following motor nerve lesions. Exp Brain Res 79:492-503.

Donoghue JP, Leibovic S, Sanes JN (1992) Organization of the forelimb area in squirrel monkey motor cortex: representation of digit, wrist, and elbow muscles. Exp Brain Res 89:1-19.

Donoghue JP, Hess G, Sanes JN (1996) Substrates and mechanisms for learning in motor cortex. In: Acquisition of motor behavior in vertebrates (Bloedel J, Ebner T, Wise SP, eds), pp 363-386. Cambridge, MA: MIT.

Ferbert A, Priori A, Rothwell JC, Day BL, Colebatch JG, Marsden CD (1992) Interhemispheric inhibition of the human motor cortex. J Physiol (Lond) 453:525-546.

Flor H, Elbert T, Knecht S, Wienbruch C, Pantev C, Birbaumer N, Larbig W, Taub E (1995) Phantom-limb pain as a perceptual correlate of cortical reorganization following arm amputation. Nature 375:482-484.

Garraghty PE, Kaas JH (1992) Dynamic features of sensory and motor maps. Curr Opin Neurobiol 2:522-527.

Gracely RH, McGrath P, Dubner R (1978) Ratio scales of sensory and affective verbal pain descriptors. Pain 5:5-18.

Hess CW, Mills KR, Murray NM (1986) Magnetic stimulation of the human brain: facilitation of motor responses by voluntary contraction of ipsilateral and contralateral muscles with additional observations on an amputee. Neurosci Lett 71:235-240.

Hess G, Donoghue JP (1994) Long-term potentiation of horizontal connections provides a mechanism to reorganize cortical motor maps. J Neurophysiol 71:2543-2547.

Hess G, Donoghue JP (1996) Long-term depression of horizontal connections in rat motor cortex. Eur J Neurosci 8:658-665.

Hess G, Aizenman CD, Donoghue JP (1996) Conditions for the induction of long-term potentiation in layer II/III horizontal connections of the rat motor cortex. J Neurophysiol 75:1765-1778.

Inghilleri M, Berardelli A, Marchetti P, Manfredi M (1996) Effects of diazepam, baclofen and thiopental on the silent period evoked by transcranial magnetic stimulation in humans. Exp Brain Res 109:467-472.

Iriki A, Pavlides C, Keller A, Asanuma H (1989) Long-term potentiation in the motor cortex. Science 245:1385-1387.

Jacobs KM, Donoghue JP (1991) Reshaping the cortical motor map by unmasking latent intracortical connections. Science 251:944-947.
Jones EG (1993) GABAergic neurons and their role in cortical plasticity in primates. Cereb Cortex 3:361-372.

Kaas JH (1991) Plasticity of sensory and motor maps in adult mammals. Annu Rev Neurosci 14:137-167.

Kaas JH, Florence SL (1997) Mechanisms of reorganization in sensory systems of primates after peripheral nerve injury. Adv Neurol 73:147-158.

Kaneko K, Kawai S, Fuchigami Y, Morita H, Ofuji A (1996) The effect of current direction induced by transcranial magnetic stimulation on the corticospinal excitability in human brain. Electroencephalogr Clin Neurophysiol 101:478-482.

Knecht S, Henningsen H, Elbert T, Flor H, Hohling C, Pantev C, Taub E (1996) Reorganizational and perceptional changes after amputation. Brain 119:1213-1219.

Kujirai T, Caramia MD, Rothwell JC, Day BL, Thompson PD, Ferbert A, Wroe S, Asselman P, Marsden CD (1993) Corticocortical inhibition in human motor cortex. J Physiol (Lond) 471:501-519.

Liepert J, Schwenkreis P, Tegenthoff M, Malin J-P (1998) The glutamate antagonist Riluzole suppresses intracortical facilitation. J Neural Transm, in press.

Mavroudakis N, Caroyer JM, Brunko E, Zegers de Beyl D (1994) Effects of diphenylhydantoin on motor potentials evoked with magnetic stimulation. Electroencephalogr Clin Neurophysiol 93:428-433.

Mavroudakis N, Caroyer JM, Brunko E, Zegers de Beyl D (1997) Effects of vigabatrin on motor potentials with magnetic stimulation. Electroencephalogr Clin Neurophysiol 105:124-127.

Max MB, Lynch SA, Muir J, Shoaf SE, Smoller B, Dubner R (1992) Effects of desipramine, amitriptyline, and fluoxetine on pain in diabetic neuropathy. N Engl J Med 326:1250-1256.

Merzenich MM, Jenkins WM (1993) Cortical representation of learned behaviors. In: Memory concepts. Basic and clinical aspects (Andersen P, Hvalby $\varnothing$, Paulsen O, Hökfeldt B, eds), pp 437-454. Amsterdam: Elsevier.

Merzenich MM, Jenkins WM (1995) Cortical plasticity, learning, and learning dysfunction. In: Maturational windows and adult cortical plasticity, Vol 23, SFI studies in the sciences of complexity (Julesz B, Kovács I, eds), pp 247-272. Reading, MA: Addison-Wesley.

Meyer BU, Röricht S, Gräfin von Einsiedel H, Kruggel F, Weindl A (1995) Inhibitory and excitatory interhemispheric transfers between motor cortical areas in normal humans and patients with abnormalities of the corpus callosum. Brain 118:429-440.

Nakamura H, Kitagawa H, Kawaguchi Y, Tsuji H, Takano H, Nakatoh S (1995) Intracortical facilitation and inhibition after paired magnetic stimulation in humans under anesthesia. Neurosci Lett 199:155-157.

Nakamura H, Kitagawa H, Kawaguchi Y, Tsuji H (1997) Intracortical facilitation and inhibition after transcranial magnetic stimulation in conscious humans. J Physiol (Lond) 498:817-823.

Netz J, Ziemann U, Hömberg V (1995) Hemispheric asymmetry of transcallosal inhibition in man. Exp Brain Res 104:527-533.

Nudo RJ, Jenkins WM, Merzenich MM (1990) Repetitive microstimulation alters the cortical representation of movements in adult rats. Somatosens Mot Res 7:463-483.

Nudo RJ, Milliken GW, Jenkins WM, Merzenich MM (1996) Usedependent alterations of movement representations in primary motor cortex of adult squirrel monkeys. J Neurosci 16:785-807.

Pascual-Leone A, Valls-Solé J, Wassermann EM, Hallett M (1994) Responses to rapid-rate transcranial magnetic stimulation of the human motor cortex. Brain 117:847-858.

Pons TP, Garraghty PE, Ommaya AK, Kaas JH, Taub E, Mishkin M (1991) Massive cortical reorganization after sensory deafferentation in adult monkeys. Science 252:1857-1860.

Ramachandran VS (1994) Phantom limbs, neglect syndromes, repressed memories, and Freudian psychology. Int Rev Neurobiol 37:291-333 (discussion, 369-272).

Ramachandran VS, Stewart M, Rogers-Ramachandran DC (1992) Perceptual correlates of massive cortical reorganization. NeuroReport 3:583-586.

Rauschecker JP (1995) Compensatory plasticity and sensory substitution in the cerebral cortex. Trends Neurosci 18:36-43.

Recanzone GH, Merzenich MM, Dinse HR (1992) Expansion of the cortical representation of a specific skin field in primary somatosensory cortex by intracortical microstimulation. Cereb Cortex 2:181-196.

Ridding MC, Rothwell JC (1995) Reorganisation in human motor cortex. Can J Physiol Pharmacol 73:218-222.

Ridding MC, Taylor JL, Rothwell JC (1995) The effect of voluntary 
contraction on cortico-cortical inhibition in human motor cortex. J Physiol (Lond) 487:541-548.

Rothwell JC (1996) The use of paired pulse stimulation to investigate the intrinsic circuitry of human motor cortex. In: Advances in magnetic stimulation. Mathematical modelling and clinical applications (Nilsson J, Panizza M, Grandori F, eds), pp 99-104. Pavia, Italy: PI-ME.

Sadato N, Zeffiro TA, Campbell G, Konishi J, Shibasaki H, Hallett M (1995) Regional cerebral blood flow changes in motor cortical areas after transient anesthesia of the forearm. Ann Neurol 37:74-81.

Sadato N, Pascual-Leone A, Grafman J, Ibanez V, Deiber MP, Dold G, Hallett M (1996) Activation of the primary visual cortex by Braille reading in blind subjects. Nature 380:526-528.

Sanes JN, Donoghue JP (1992) Organization and adaptability of muscle representations in primary motor cortex. In: Control of arm movement in space, Vol 22 (Caminiti R, Johnson PB, Burnod Y, eds), pp 103-127. New York: Springer.

Sanes JN, Donoghue JP (1997) Static and dynamic organization of motor cortex. Adv Neurol 73:277-296.

Sanes JN, Suner S, Lando JF, Donoghue JP (1988) Rapid reorganization of adult rat motor cortex somatic representation patterns after motor nerve injury. Proc Natl Acad Sci USA 85:2003-2007.

Sanes JN, Suner S, Donoghue JP (1990) Dynamic organization of primary motor cortex output to target muscles in adult rats. I. Long-term patterns of reorganization following motor or mixed peripheral nerve lesions. Exp Brain Res 79:479-491.

Sanes JN, Donoghue JP, Thangaraj V, Edelman RR, Warach S (1995) Shared neural substrates controlling hand movements in human motor cortex. Science 268:1775-1777.

Spengler F, Dinse HR (1994) Reversible relocation of representational boundaries of adult rats by intracortical microstimulation. NeuroReport 5:949-953.

Tergau F, Tormos JM, Paulus W, Pascual-Leone A, Ziemann U (1997) Effects of repetitive transcranial magnetic stimulation (rTMS) on cortico-spinal and cortico-cortical excitability. Neurology 48:A107.

Wang H, Wang X, Scheich H (1996) LTD and LTP induced by transcranial magnetic stimulation in auditory cortex. NeuroReport 7:521-525

Wassermann EM, McShane LM, Hallett M, Cohen LG (1992) Noninvasive mapping of muscle representations in human motor cortex. Electroencephalogr Clin Neurophysiol 85:1-8.

Woody CD, Gruen E, Birt D (1991) Changes in membrane currents during Pavlovian conditioning of single cortical neurons. Brain Res 539:76-84.

Yang TT, Gallen CC, Ramachandran VS, Cobb S, Schwartz BJ, Bloom FE (1994) Noninvasive detection of cerebral plasticity in adult human somatosensory cortex. NeuroReport 5:701-704.

Ziemann U, Lönnecker S, Paulus W (1995) Inhibition of human motor cortex by ethanol. A transcranial magnetic stimulation study. Brain 118:1437-1446.

Ziemann U, Lönnecker S, Steinhoff BJ, Paulus W (1996a) The effect of lorazepam on the motor cortical excitability in man. Exp Brain Res 109:127-135.

Ziemann U, Lönnecker S, Steinhoff BJ, Paulus W (1996b) Effects of antiepileptic drugs on motor cortex excitability in humans: a transcranial magnetic stimulation study. Ann Neurol 40:367-378.

Ziemann U, Rothwell JC, Ridding MC (1996c) Interaction between intracortical inhibition and facilitation in human motor cortex. J Physiol (Lond) 496:873-881. 